\title{
Seasonal food of Ceratomegilla notata (Coleoptera: Coccinellidae) in mountain environments of Northern Italian Alps
}

\author{
CARlo RICCI and Luigi PONTI \\ Department of Arboriculture and Plant Protection, University of Perugia, Borgo XX Giugno, 06121 Perugia, Italy; \\ e-mail: cricci@unipg.it
}

Key words. Coccinellidae, Ceratomegilla notata, gut content, foraging behaviour, crops, wild plants, aphids, fungi spores, pollens

\begin{abstract}
The aim of this study was to clarify the diet of Ceratomegilla notata (Laicharting), a common species in different mountain habitats of the Palearctic region. In Italy it is found only in alpine ecosystems between $800-1700 \mathrm{~m}$. In these areas, up to 1200 $\mathrm{m}$, various crops (e.g., maize, potatoes) are present. The high meadows are cut for hay. From 2002 to 2003 investigations on the foraging behaviour of this ladybird were carried out in mountain habitats (six near Villabassa, in Bolzano province, and six near Soraga, in Trento province) and in the "Paradisia" Botanic Garden (Gran Paradiso National Park). C. notata adults and larvae were found on the flowering plants, especially those infested by aphids. The study of their diet was done taking random D-Vac samples of 20 adults and 20 larvae/habitat every 15 days, between July and September. The influence of the haymaking on C. notata populations was also evaluated.

In agricultural fields the ladybirds prey on Rhopalosiphum maidis (Fitch), R. padi (L.) on maize and on Acyrthosiphon pisum (Harris) and Therioaphis luteola (Born.) on Trifolium pratense L. In the natural pastures, adults and larvae feed on Cavariella theobaldi G. \& B. found on Heracleum sphondylium (Umbelliferae), Sitobion avenae L. on Avena sativa L., Megoura viciae (B.) and A. pisum on Vicia cracca L., Uroleucon jaceae (L.) on Cirsium arvense Scop., U. cichorii (Koch) on Hypochaeris radicata L. and Macrosiphum weberi Born. on Scabiosa sp. A study of the gut contents revealed the presence of aphids, Umbelliferae pollens and spores of fungi (e.g., Alternaria spp., Helminthosporium spp., Puccinia spp.). Statistically significant associations between different food sources were more frequent for adults than for larvae in both 2002 and 2003. Thrips are an important prey of this ladybird in the absence of aphids. C. notata is an important aphidophagous species in Alpine habitats.
\end{abstract}

\section{INTRODUCTION}

Ceratomegilla notata (Laich.), a rare species found in some sub-mountain and mountain areas of the Palearctic region, has recently become a component of lowland areas of Bohemia and adapts easily to man-changed environments such as agricultural landscapes (Horion, 1961; Savoiskaya, 1983; Hodek \& Honěk, 1996). The ladybird is present also in Poland at low levels (P. Ceryngier, pers. comm.). In Italy it is present in some areas of alpine ecosystems. Few data are available about the diet of this species. Savoiskaya (1983) reported C. notata as a predator of aphids of Urtica sp.

The aim of this study was to study and report the occurrence, diet and foraging behaviour of this ladybird in Alpine ecosystems. In fact the feeding habits of $C$. notata have rarely been studied.

\section{MATERIAL AND METHODS}

The investigations were carried out in 2002 and 2003, in natural pastures and in agroecosystems of the eastern and western Italian Alps. The eastern sites studied were natural pastures near La Thuile (1400 m) (Aosta) and the Alpine Garden "Paradisia" (1700 m) in the Gran Paradiso National Park (1254 m) (Cogne, Aosta). The western sites investigated were natural meadows around Soraga $(1242 \mathrm{~m})$ (Trento), Brunico $(838 \mathrm{~m})$, Villabassa (1158 m) and Tesido (1219 m) (Bolzano), as well as natural pastures of the Armentara area $(1580 \mathrm{~m})$ (Bolzano), and natural meadows around Cortina D'Ampezzo $(1211 \mathrm{~m})$ (Belluno).
In the Alpine habitats, the distribution of $C$. notata was observed from low to high altitudes. In the morning between 10.00 a.m. -12.00 noon, visual observations on flowering plants were carried out to record the presence of this coccinellid and its foraging behaviour. Also the flowering plants and the aphid infestations were recorded. Plant and aphid species were identified. Moreover, phenological phases of plants and agricultural practices were recorded. The influence of harvesting on $C$. notata foraging behaviour was considered.

The study of $C$. notata diet was done taking random D-Vac samples of 20 adults and 20 larvae in meadows near Villabassa every 15 days between July and September. In the laboratory, the adults and larvae were dissected at stereomicroscope; the gut content was observed at the light microscope, aphids and other preys' remains were recorded (presence or absence); pollens and fungi spores were counted.

We tested for positive and negative associations between the presence of different food sources in the digestive tracts of individual $C$. notata adults and larvae. For this purpose, we derived for each sample the number of coccinellid individuals with remains of a particular food in the gut. In other words, correlation coefficients were computed on the basis of whether individual ladybirds do or do not have a particular food item in their gut. We also tested correlation coefficients for statistical significance.

Seasonal dynamics of food in relation to habitats are not reported in the present paper and will be published separately.

\section{RESULTS}

The adult captures of $C$. notata in the Italian Alps revealed that the species is distributed between 800-1700 $\mathrm{m}$ on high meadows and on field crops (e.g., maize at 

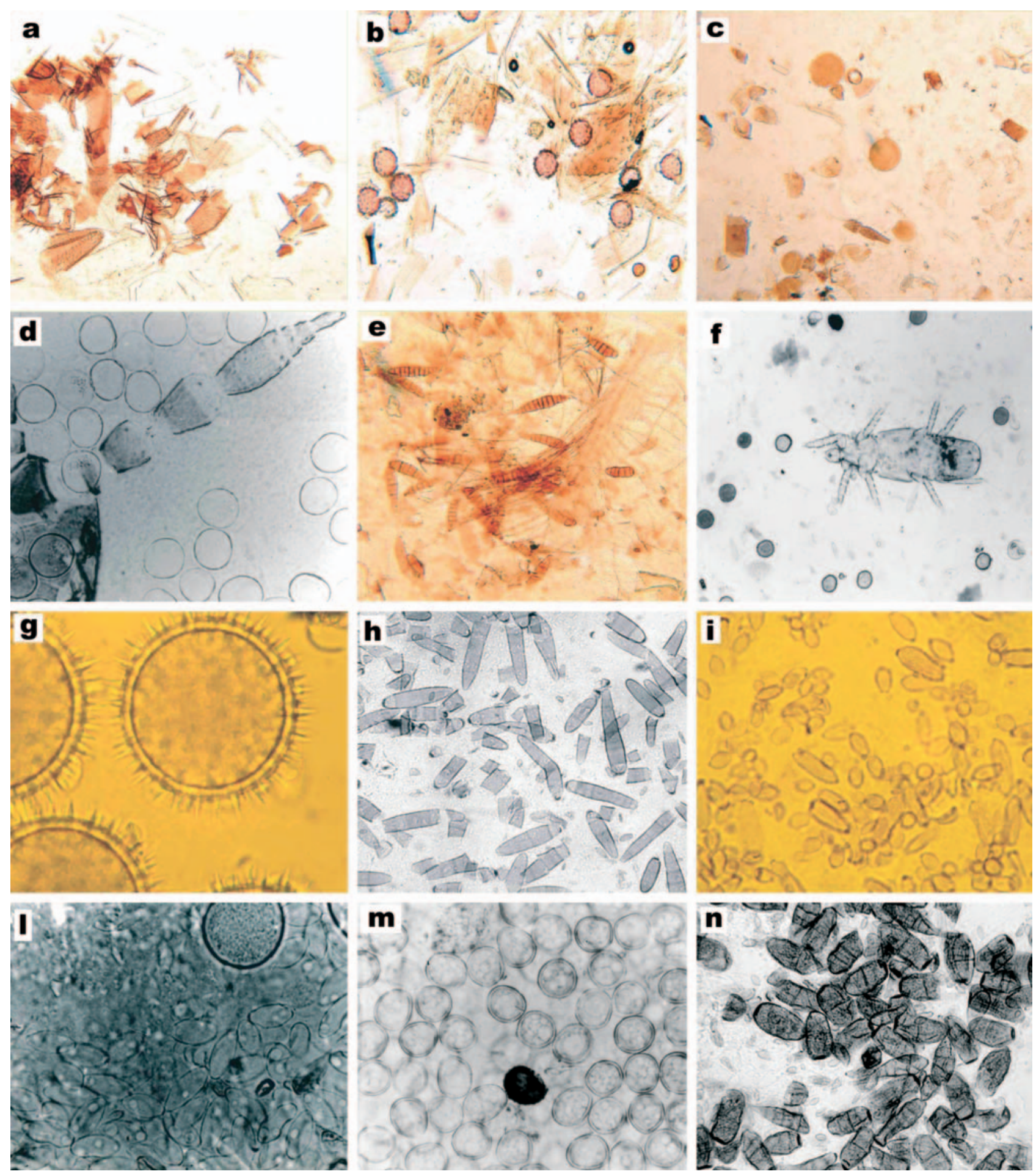

Fig. 1. Examples of gut content observed in Ceratomegilla notata: (a) aphid remains; (b) aphid remains and Carduus spp. pollens; (c) aphid remains and maize pollen; (d) thripid remains among Graminaceae pollens; (e) thripid wings among Alternaria spp. spores; (f) mite among Puccinia spp. spores; (g) Compositae pollens; (h) Helminthosporium spp. conidia; (i) Cladosporium spp. conidia; (1) Oidium spp. conidia among pollens; (m) Puccinia spp. spores; (n) Stemphylium spp. conidia.

$800-1100 \mathrm{~m})$. In the eastern Alps the ladybird is common on Compositae (e.g., Carduus spp.) and Umbelliferae (e.g., Heracleum sphondylium L.) found in the "Paradisia" Botanic Garden. In this habitat, C. notata adults and larvae feed on pollens and aphids, in particular Cavariella theobaldi G. \& B. infesting $H$. sphondylium. This ladybird also preys on the same aphid on the same plants in natural pastures. In the agricultural fields of western Alps, this species feeds on Rhopalosiphum maidis (Fitch) and R. padi (L.) on maize, Therioaphis luteola (Born.) and Acyrthosiphon pisum (Harris) on Trifolium pratense L., Sitobion avenae (F.) on Avena sativa L. It also feeds on pollens of these plant species. In natural meadows the ladybird preys on Megoura viciae 

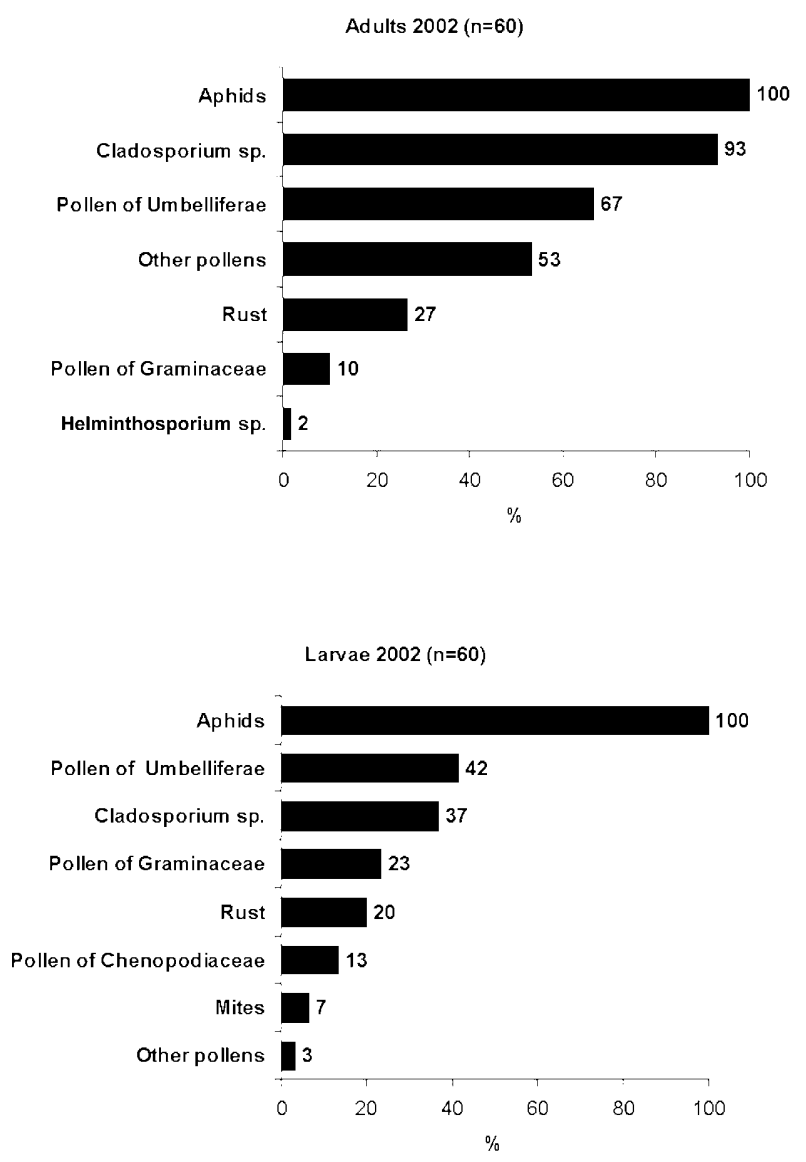
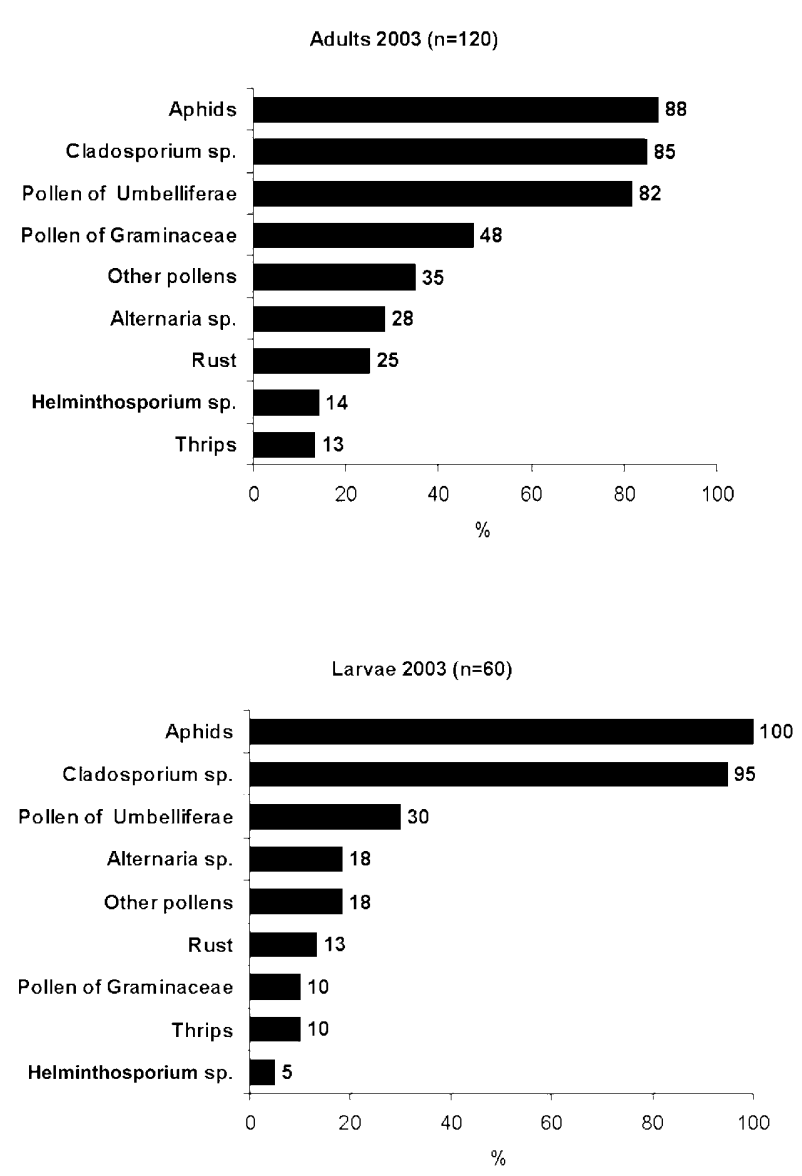

Fig. 2. Percentage of Ceratomegilla notata larvae and adults showing different food remains for 2002 and 2003.

(B.) infesting Vicia cracca L., Uroleucon jaceae (L.) on Cirsium arvense Scop., U. cichorii (Koch) on Hypochaeris radicata L., Macrosiphum weberi (Born.) on Scabiosa sp., and C. theobaldi G. \& B. on H. sphondylium $\mathrm{L}$. This last host plant belongs to Umbelliferae and is a dominant plant in natural pastures and wild areas, flowering all summer long. When the high meadow hay is cut (twice: beginning July and end August), the ladybird adults fly to wild areas where they forage on aphids and pollen of H. sphondylium. The larvae remain in the field and collect saprophytic fungi (e.g., Cladosporium spp.) commonly found on straw moistened by frequent rain.

The study of gut content of both adults and larvae revealed the presence of aphids, thrips, mites, pollens of various plants (e.g., Graminaceae, Compositae and Umbelliferae) and spores of fungi (e.g., Alternaria spp., Puccinia spp., Cladosporium spp., Helminthosporium spp., and other unidentified species) (Fig. 1). The percentage (\%) of $C$. notata larvae and adults showing different food remains in their gut is reported in Fig. 2.

In 2002 , correlation coefficients related to the larvae of C. notata were not statistically significant, while in 2003 there was a positive correlation between the presence of Graminaceae and Umbelliferae pollens and between Puccinia spp. spores and other pollens $(\mathrm{P} \leq 0.05)$ (Table 1). All larvae dissected contained aphid remains. A significant $(P \leq 0.05)$ negative correlation coefficient between presence of Umbelliferae pollens and other pollens was found for C. notata adults in 2002; a negative association $(\mathrm{P} \leq 0.01)$ between the presence of thrips and aphids was evident from the observations carried out on the adults of C. notata in 2003 (Table 2). These results may indicate that thrips are an important prey of $C$. notata in absence of aphids. Statistically significant positive associations between different food sources [Graminaceae pollens and aphids; Helminthosporium spp. and Umbelliferae pollens $(\mathrm{P} \leq 0.05)$; other pollens and Umbelliferae pollens; Cladosporium spp. spores and Umbelliferae pollens; Helminthosporium spp. spores and Cladosporium spp. spores ( $\mathrm{P}$ $\leq 0.01)$ ] were more frequent for adults than for larvae in both 2002 and 2003. When the ladybirds feed on maize aphids, they also collect the pollen; and those on Umbelliferae seem to collect both the pollen and Helminthosporium spp. spores infesting the plant. The other pollens are collected together with Umbelliferae pollens since they all are flowering at the same time. The different fungal

TABLE 1. Significant correlation coefficients computed on the basis of number of Ceratomegilla notata larvae per sample having a particular food item in gut in 2002 and 2003 (* $\mathrm{P}$ $\leq 0.05$ ).

\begin{tabular}{lcc}
\hline \multirow{2}{*}{ Food item } & \multicolumn{2}{c}{ Year } \\
\cline { 2 - 3 } & 2002 & 2003 \\
\hline Graminaceae pollen/Umbelliferae pollen & - & $0.278^{*}$ \\
Puccinia spp./Other pollens & - & $0.265^{*}$ \\
\hline
\end{tabular}


TABLE 2. Significant correlation coefficients computed on the basis of number of Ceratomegilla notata adults per sample having a particular food item in gut in 2002 and $2003(* \mathrm{P} \leq$ $0.05 ; * * \mathrm{P} \leq 0.01)$.

\begin{tabular}{lcc}
\hline \multirow{2}{*}{ Food item } & \multicolumn{2}{c}{ Year } \\
\cline { 2 - 3 } & 2002 & 2003 \\
\hline Thrips/Aphids & - & $-0.371^{* *}$ \\
Graminaceae pollens/Aphids & - & $0.191^{*}$ \\
Other pollens/Umbelliferae pollens & $-0.306^{*}$ & $0.293^{* *}$ \\
Cladosporium spp./ Umbelliferae pollens & - & $0.241^{* *}$ \\
Helminthosporium spp./ Umbelliferae pollens & - & $0.208^{*}$ \\
Helminthosporium spp./ & - & $0.571^{* *}$ \\
Cladosporium spp. spores & & \\
\hline
\end{tabular}

spores are correlated since they are present in the straw and are also infecting these plants.

\section{DISCUSSION AND CONCLUSIONS}

C. notata is a common ladybird in Italian alpine mountains from 800 to $1700 \mathrm{~m}$. Its diet consists of various aphid species, thrips, mites, Graminaceae, Compositae and Umbelliferae pollens, spores of fungi (mainly Alternaria spp. and Cladosporium spp.).

This ladybird plays an important role in controlling harmful aphids (e.g., $R$. maidis and $R$. padi on maize) in crops from 800 to $1100 \mathrm{~m}$. In natural pastures both adults and larvae of $C$. notata prefer $C$. theobaldi G. \& B., an aphid infesting $H$. sphondylium.

Our results also show that thrips are an important prey of $C$. notata in absence of aphids; the food specificity is more pronounced in adults than in larvae. However, $C$. notata's diet varies depending on the food sources available at different times and in the different habitats.

ACKNOWLEDGEMENTS. The authors would like to thank the following specialists on taxonomy: S. Barbagallo (Catania University) for the identification of aphids, V. Raggi and G. Ricciardelli d'Albore, and M. Bencivenga and D. Donnini (Perugia University) for identification of fungi, pollens and plants, respectively. We are grateful to A. Mommi for photographic service, L. Bartoli and D. Fortini for their help during the field and laboratory work, and C. Bennett for editing and revising the English text.

\section{REFERENCES}

Hodek I. \& HonĚK A. 1996: Ecology of Coccinellidae. Kluwer, Dordrecht, $464 \mathrm{pp}$.

Horion A. 1961: Faunistik der mitteleuropäischen Käfer. Coccinellidae. Bd. 8. Goecke and Evers, München, quoted in Hodek I. \& Honěk A. (1996): Ecology of Coccinellidae. Kluwer, Dordrecht, p. 100.

SavoISKAYA G.I. 1983: Kokcinellidy. Izdatelstvo Nauka Kazakhskoi SSR, Alma-Ata, 246 pp. (in Russian).

Received October 18, 2004; revised and accepted April 4, 2005 